$$
\text { CONE-971037-1 SPN097.1965C }
$$

To be presented at the $23^{\text {rd }}$ International Symposium for Testing and Failure Analysis, October 27 - 31, 1997, Santa Clara, $C A$

\section{Electrical and Chemical Characterization of FIB-Deposited Insulators}

\author{
Ann N. Campbell, Danelle M. Tanner, Edward Adams*, Margaret Gibson*, \\ Marsha Abramo*, Andrew Doyle**, Diane K. Stewart**, and Jerry M. Soden
}

RECEIVED
AUG 11997

O \& I

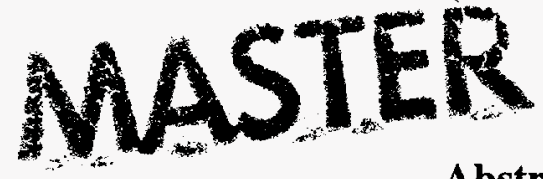

Abstract

The electrical and chemical properties of insulators produced by codeposition of siloxane compounds or TEOS with oxygen in a focused ion beam (FIB) system were investigated. Metal-insulator-metal capacitor structures were fabricated and tested. Specifically, leakage current and breakdown voltage were measured and used to calculate the effective resistance and breakdown field. Capacitance measurements were performed on a subset of the structures. It was found that the siloxanebased FIB-insulators had superior electrical properties to those based on TEOS. Microbeam Rutherford backscattering spectrometry analysis and Fourier transform infrared spectroscopy were used to characterize the films and to help understand the differences in electrical behavior as a function of gas chemistry and deposition conditions. Finally, a comparison is made between the results presented here, previous results for FIB-deposited insulators, and typical thermally-grown gate oxides and interlevel dielectric $\mathrm{SiO}_{2}$ insulators.

\section{Introduction}

The ability to deposit insulator materials in a FIB system has become increasingly important for device modification of submicron, multilevel integrated circuit (IC) technologies. Most commercially available FIB systems now have the capability to form insulator materials by ion-beam induced chemical vapor deposition from a siloxane or TEOS precursor, which may or may not be codeposited with oxygen. FIBdeposited insulators permit repairs at different metallization levels to be electrically isolated from each other as well as allowing passivation of FIB-deposited conductors $[1,2]$. The insulating materials formed in the FIB system typically consist of $\mathrm{Si}, \mathrm{O}$, and $\mathrm{Ga}$, and may contain $\mathrm{C}$ and other trace impurities as well. The ion source for the commercial FIB systems is a Ga liquid metal ion source, and so the presence of $\mathrm{Ga}$ in the deposits cannot be avoided. The presence of $\mathrm{C}$ has been reported when insulator deposition was performed using a TEOS precursor but without codeposition with oxygen [3].

It is important to both understand and improve the electrical properties of FIB-deposited insulators so they can be used with confidence to perform circuit modifications. Further, there is interest in developing higher quality insulators to support high reliability applications of FIB-modified ICs.

Previous work has characterized the electrical and chemical behavior of insulators deposited in commercial FIB systems using liquid $\mathrm{Ga}$ ion sources. John Baker studied the properties of insulators deposited from TEOS (tetraethoxysilane) alone (i.e., without oxygen) [3] by fabricating metal-insulator-metal (MIM) capacitor structures with FIB-insulators ranging in thickness from 0.1 to $0.4 \mu \mathrm{m}$. Baker reported resistivity values ranging from $\mathrm{k} \Omega-\mathrm{cm}$ to $\mathrm{G} \Omega-\mathrm{cm}$ and breakdown voltages ranging from $7 \mathrm{~V}$ to $>100 \mathrm{~V}$. He also observed that the resistivity of the deposits increased by as much as two orders of magnitude over a period of 1 week. Auger analysis indicated that the films deposited from TEOS alone contained $\mathrm{Si}, \mathrm{O}, \mathrm{C}$, and $\mathrm{Ga}[3]$. The percentage of $\mathrm{O}$ was less than stoichiometric and the fraction of $\mathrm{C}$ was quite large [4]. Marsha Abramo and coworkers $[2,5,6]$ have studied the electrical and chemical properties of FIB-insulator materials formed by using a siloxane precursor codeposited with oxygen. Their test approach uses FIB micromachining to create a FIB repair in a 2-level metal structure. The leakage current is measured through a FIB insulator layer formed between metal-1 and metal-2 Al metallization levels approximately $1 \mu \mathrm{m}$ apart (vertically). Leakage current in the pA range was measured, corresponding to an effective resistance of $\sim 10^{12} \Omega$. Microbeam Rutherford backscattering spectrometry (RBS) analysis and micro Fourier transform infrared spectroscopy (FTIR) were used to show that the films contain $\mathrm{Si}$ and $\mathrm{O}$ in stoichiometric proportion, are free of $\mathrm{C}$, and contain from $8-11$ atomic percent $\mathrm{Ga}$.

In the present work, the electrical and chemical properties of FIB-deposited insulators formed from three different gas chemistries were studied. Specifically, we examined the insulators formed by codeposition of two siloxane compounds and TEOS with oxygen in a FIB system. While most of the 


\section{DISCLAMIER}

Portions of this document may be illegible in electronic image products. Images are produced from the best available original document. 
previous studies of FlB-insulator electrical properties have focused on characterizing the leakage current and effective resistance, our goal was to develop a more fundamental understanding of the electrical behavior of the FIB-deposited insulator materials. Our approach was to characterize the $I-V$ behavior of the insulator films to the point of breakdown as well as to understand the chemical properties of the films. These data may allow us to begin to develop a fundamental understanding of these insulators and how the FIB deposition processes can be improved.

\section{Experimental Approach}

Metal - insulator - metal capacitor structures were fabricated in the FIB system to allow characterization of the electrical properties of FIB-deposited insulators. The FIB-insulators were formed by codeposition of Si-containing precursors with $\mathrm{O}_{2}$. The Si-containing precursors used in this study were tetramethylcyclotetrasiloxane (TMCTS) [7,8], octamethylcyclotetrasiloxane (OMCTS), and tetraethoxysilane (TEOS) [3]. Insulator film deposition was performed in a Micrion 9500 FIB system with $50 \mathrm{keV}$ accelerating voltage and a $5 \mathrm{~nm}$ minimum spot size. In addition, a small set of TMCTS insulators was fabricated in a Micrion 9000 FIB system with a $30 \mathrm{keV}$ accelerating voltage and $25 \mathrm{~nm}$ minimum spot size. The deposition processes were optimized prior to these experiments. The conductive top electrodes were deposited from a $\mathrm{W}(\mathrm{CO})_{6}$ precursor in a Micrion 9000 system with 30 $\mathrm{keV}$ accelerating voltage and $25 \mathrm{~nm}$ minimum spot size. All depositions were performed at room temperature.

The process parameters for both insulator and conductor deposition are summarized in Table 1. The term "deposition yield" refers to the amount of material deposited per unit ion dose. The ion dose is the total number of $\mathrm{Ga}$ ions impinging per unit area and is expressed in terms of $\mathrm{nC} / \mu^{2} \mathrm{~m}^{2}$. The entry in Table 1 for "Relative Deposition Yield" compares the yields of the three insulator deposition processes. The TMCTS-based process yields insulator films 8.5 times thicker than the TEOSbased process for a given ion dose. The pressures of siloxane/TEOS and oxygen given in Table 1 are measured in the delivery lines (not the chamber). An increase in the line pressure for one of the gas species translates into an increase in the partial pressure of that species in the FIB chamber. The optimum pressure settings were determined empirically. The actual partial pressures for each species in the chamber were not measured.

Our goal was to achieve breakdown of the capacitors at a moderate voltage $(<30 \mathrm{~V})$, and it was estimated that a FIBinsulator thickness of $0.1-0.15 \mu \mathrm{m}$ would be appropriate. The capacitors were fabricated in the FIB system by depositing a $0.12-0.14 \mu \mathrm{m}$ insulating layer followed by a $0.5 \mu \mathrm{m} \mathrm{W}$ conductive top electrode onto 6" silicon wafers which were previously metallized with $0.6 \mu \mathrm{m}$ of Al. A schematic representation of the capacitor structure used in the study is shown in Fig. 1 and a FIB cross section of one of the capacitors is shown in Fig. 2.

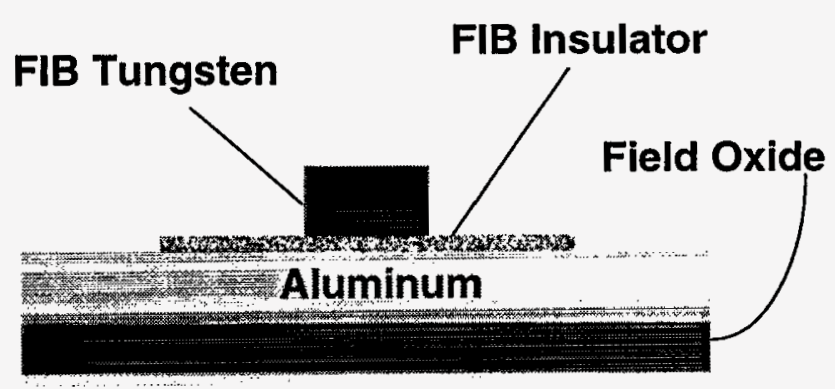

\section{Silicon Substrate}

Fig. 1. Schematic cross section of the capacitor structure used in this study.

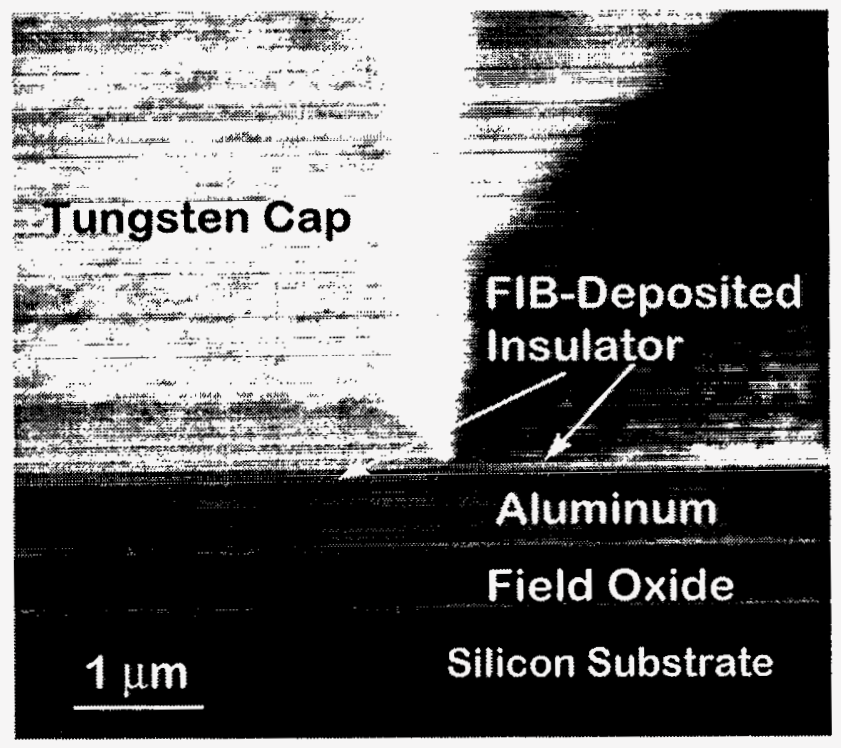

Fig. 2. FIB cross section of one of the capacitors fabricated from TMCTS $+\mathrm{O}_{2}$ in the $30 \mathrm{keV}$ FIB system.

The thickness of the FIB-insulator deposits was controlled by determining the thickness deposited per unit ion dose. Several calibration deposits were made with ion doses ranging from approximately 0.3 to $2.0 \mathrm{nC} / \mu^{2}$. The FIB-insulator deposits were cross sectioned to determine the thickness of each. The results of this experiment showed that the deposited thickness increased linearly with ion dose. The appropriate ion dose was selected to achieve a deposited thickness of 0.12 $0.14 \mu \mathrm{m}$. For example, for the TMCTS $+\mathrm{O}_{2}$ gas mixture in the $30 \mathrm{keV}$ system, a dose of $0.15 \mathrm{nC} / \mu^{2}$ yielded a deposited thickness of $0.13 \mu \mathrm{m}$. Profilometry was used to verify the thickness of the deposits. The estimated error in thickness is $+1-$ $10 \%$. 
Table 1

Deposition Conditions

\begin{tabular}{|l|c|c|c|c|c|c|c|c|}
\hline $\begin{array}{l}\text { FIB } \\
\text { Deposited } \\
\text { Film }\end{array}$ & $\begin{array}{l}\text { Accel. } \\
\text { Voltage } \\
(\mathbf{k e V})\end{array}$ & $\begin{array}{l}\text { Minimum } \\
\text { spot size } \\
(\mathbf{n m})\end{array}$ & $\begin{array}{l}\text { Beam } \\
\text { current } \\
(\mathbf{n A})\end{array}$ & $\begin{array}{l}\text { Pixel } \\
\mathbf{d w e l l} \\
\text { time }(\mu \mathbf{s})\end{array}$ & $\begin{array}{l}\text { Pixel } \\
\text { spacing } \\
(\mu \mathbf{m})\end{array}$ & $\begin{array}{l}\text { Relative } \\
\text { Deposition } \\
\text { Yield }\end{array}$ & $\begin{array}{l}\text { Siloxane } \\
\text { or TEOS } \\
\text { pressure } \\
(\text { torr })\end{array}$ & $\begin{array}{l}\text { Oxygen } \\
\text { pressure } \\
\text { (torr) }\end{array}$ \\
\hline TMCTS & 30 & 25 & 1.7 & 0.5 & 0.75 & 8.5 & 0.5 & 3.0 \\
\hline TMCTS & 50 & 5 & 6 & 0.5 & 0.6 & 8.5 & 0.2 & 3.5 \\
\hline OMCTS & 50 & 5 & 10 & 0.2 & 0.75 & 5.5 & 0.2 & 3.5 \\
\hline TEOS & 50 & 5 & 10 & 0.2 & 0.75 & 1 & 0.8 & 3.5 \\
\hline $\begin{array}{l}\text { W top } \\
\text { electrode }\end{array}$ & 30 & 25 & 1.7 & 0.75 & 0.75 & - & & \\
\hline
\end{tabular}

During test structure development it was found expedient to make the FIB-insulator pads considerably larger $(200 \mu \mathrm{m} \times 200$ $\mu \mathrm{m})$ than the top $\mathrm{W}$ contacts $(60 \mu \mathrm{m} \times 60 \mu \mathrm{m})$ so the overspray would not short out the capacitor. Overspray refers to the halo of conductive material that forms around FIB-deposited conductors. The overspray occurs because a certain amount of the FIB-deposited material is sputtered by the ion beam and redeposits nearby. When the capacitors were shorted by overspray they exhibited leakage currents in the $\mathrm{mA}$ range, compared with nA-scale leakage current for "normal" capacitors. An alternative approach would involve a clean-up mill to remove the $\mathrm{W}$ overspray. However, it was decided not to use this approach to avoid any possibility of damaging the FIB-insulator during milling to remove the conductive overspray.

The $\mathrm{W}$ top electrode was made as thick as possible $(\sim 0.5$ $\mu \mathrm{m})$ to prevent damage to the insulator during probing. Whereas a $1 \mu \mathrm{m}$ thickness would have been preferred, the long process times $(\sim 4 \mathrm{hr}$. to achieve a $1 \mu \mathrm{m}$ thick pad) placed a practical upper limit on the top electrode thickness.

\section{Measurements and Results}

Electrical Characterization. Leakage current and breakdown voltage were measured for all of the capacitors. The effective resistance and breakdown field were calculated from these measurements. Leakage current was measured with $3 \mathrm{~V}$ between the top (W pad) and bottom (Al layer) of the capacitor, and then an $I-V$ sweep was performed to the point of electrical breakdown. The leakage and oxide breakdown tests were performed with an Electroglas 2001X automated prober with a Hewlett-Packard 4062 parametric test system. A special probe card with two probes spaced $500 \mu \mathrm{m}$ apart was used for making simultaneous contact to the tungsten top cap and the aluminum bottom plate as shown schematically in Fig. 3. The voltage was linearly stepped and the current was measured at each step. Typical $I-V$ curves for various FIB-insulators evaluated in this study are shown in Fig. 4, plotted on a logarithmic scale, and Fig. 5, plotted on a linear scale. The non- linear shape of the I-V curves shown in Fig. 5 is very similar to those reported by Abramo [6] and Baker [3]. Breakdown was recorded when the current was ten times higher than the previous step or if the current met the compliance value, 100 $\mathrm{mA}$.

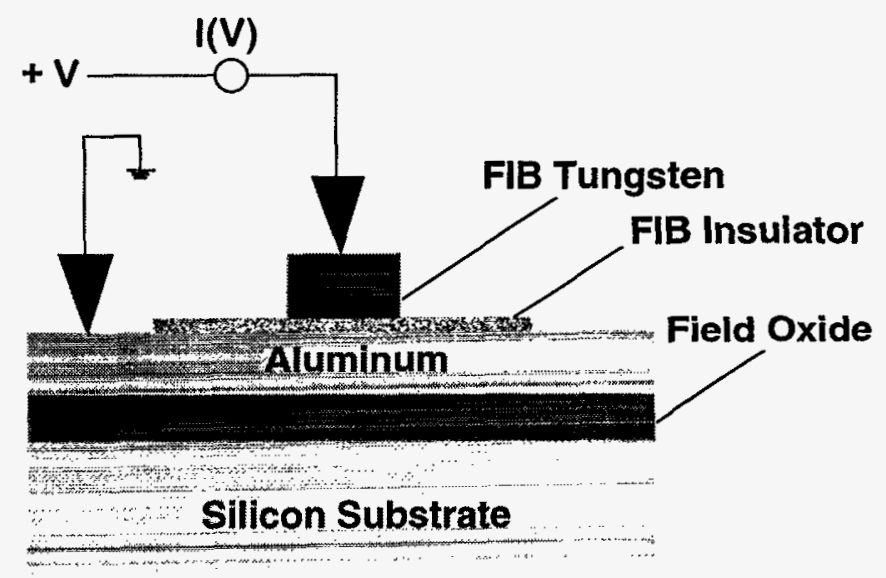

Fig. 3 Schematic representation of test configuration for the FIB-deposited capacitor structures.

Capacitance measurements were performed on a subset of the TMCTS films with a low-noise Cascade Microtech semiautomatic prober with a Hewlett-Packard 4284A LCR meter. The LCR meter measured the change in charge, dQ, due to a change in voltage, $\mathrm{dV}$, provided by a small-signal ac voltage applied at $100 \mathrm{kHz}$. Based on the known dielectric constant for $\mathrm{SiO}_{2}$ and the area and thickness of the FIB capacitor structures, it was anticipated that the capacitance of the structures would be in the single-digit $\mathrm{pF}$ range. The functionality of the system was tested on a known $575 \mathrm{fF}$ ceramic capacitor to ensure that we would be able to make accurate capacitance measurements in the $\mathrm{pF}$ range. The measured capacitance values (Table 2) are about a factor of 4 times larger than expected. The likely 
reasons for this behavior are described in the Discussion section.

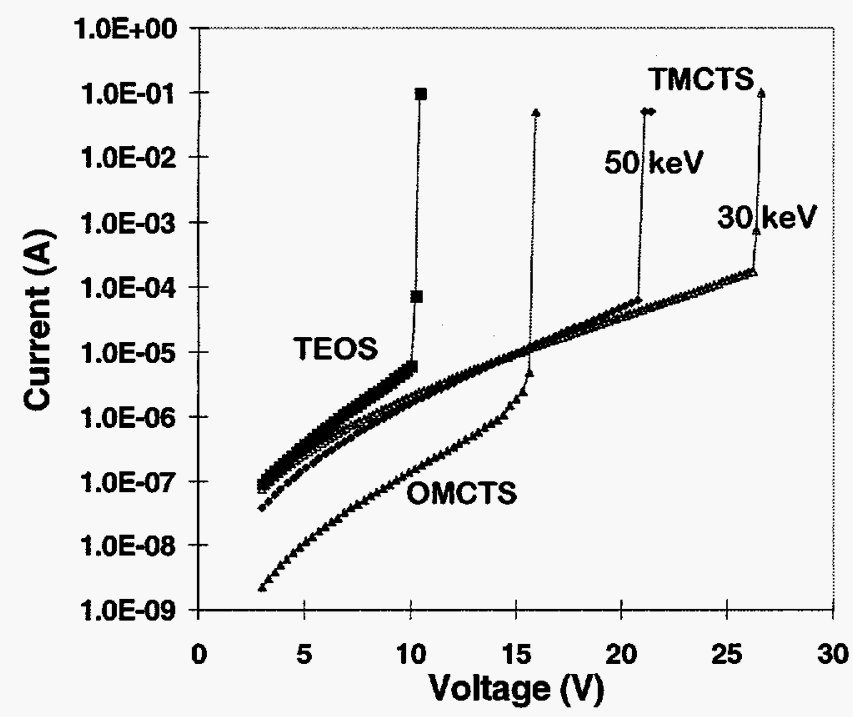

Fig. 4. Typical $I-V$ curves for the FIB-insulators produced in this study.

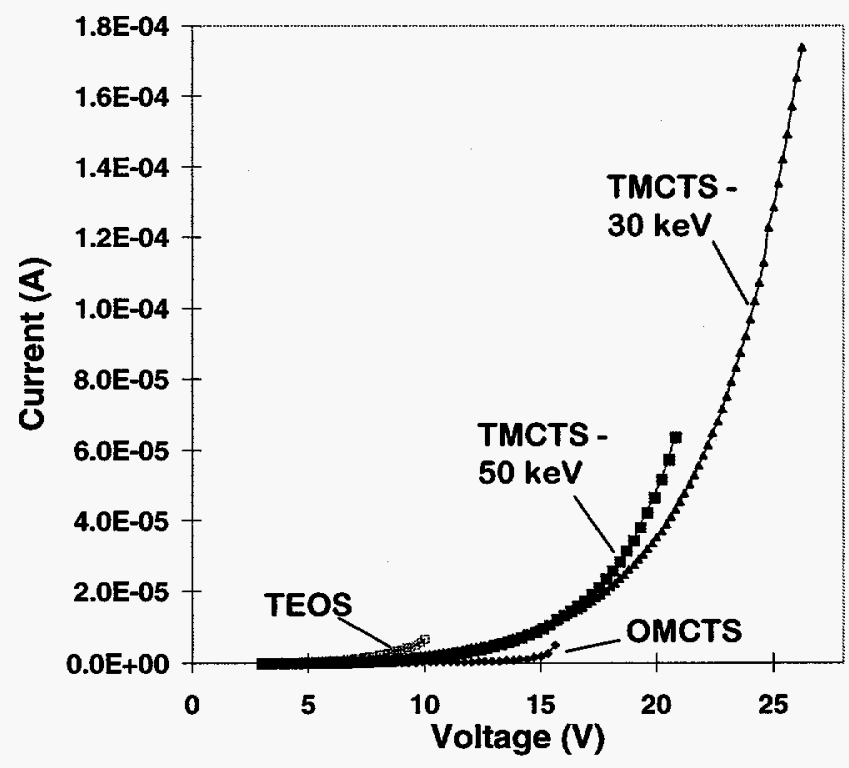

Fig 5. Typical $I-V$ curves represented on a linear scale.

The results of the leakage, breakdown, and capacitance measurements for the FIB insulators are summarized in Tables 2 - 5. Each table summarizes the data for a given set of deposition conditions. The breakdown field $E_{B D}$ was estimated from the breakdown voltage $V_{B D}$ and measured insulator thickness $t_{0 X}$ by using Equation 1:

$$
E_{B D}=V_{B D} / t_{O X}
$$

The effective resistance $R_{E F F}$ was calculated from the leakage current $I_{L E A K}$ at $3 \mathrm{~V}$ by using Equation 2:

$$
R_{E F F}=V_{A P P D} / I_{L E A K}
$$

where $V_{A P P L}$ is the applied voltage (3V). The measurement at 3 $\mathrm{V}$ represents the actual use condition for most state-of-the-art IC technologies. The bottom row of each table gives the average of the various parameters. The average $I_{L E A K}$ is computed from the leakage current values in the table. The average $R_{E F F}$ is calculated from the average of $I_{L E A K}$.

It is clear from Tables 2 - 5 that capacitors fabricated with the TMCTS $+\mathrm{O}_{2}$ films exhibit the highest breakdown field. The average $E_{B D}$ is $1.59 \mathrm{MV} / \mathrm{cm}$ for the films deposited at 50 $\mathrm{keV}$, and $1.99 \mathrm{MV} / \mathrm{cm}$ for those deposited at $30 \mathrm{keV} . E_{B D}$ is $0.99 \mathrm{MV} / \mathrm{cm}$ for the OMCTS-based insulators and $0.83 \mathrm{MV} / \mathrm{cm}$ for the TEOS-based insulators, both fabricated at $50 \mathrm{keV}$.

Table 2

TMCTS $+\mathrm{O}_{2}$ Insulators, $50 \mathrm{keV}$

\begin{tabular}{|c|c|c|c|c|c|c|}
\hline $\begin{array}{c}\text { Pad } \\
\text { No. }\end{array}$ & $\begin{array}{c}t_{O X} \\
(\mu \mathrm{m})\end{array}$ & $\begin{array}{c}\boldsymbol{V}_{B D} \\
(\mathbf{V})\end{array}$ & $\begin{array}{c}\boldsymbol{E}_{\boldsymbol{B D}} \\
(\mathbf{M V} / \mathbf{c m})\end{array}$ & $\begin{array}{c}\boldsymbol{I}_{L E A K}(\mathbf{A}) \\
\text { at 3V }\end{array}$ & $\begin{array}{c}\boldsymbol{R}_{\boldsymbol{E} F F} \\
(\mathbf{M} \boldsymbol{\Omega}) \\
\mathbf{a t ~ 3 V}\end{array}$ & $\begin{array}{c}\text { Capacitance } \\
(\mathbf{p F})\end{array}$ \\
\hline 1 & 0.13 & 20.8 & 1.60 & $3.98 \mathrm{E}-8$ & 75 & \\
\hline 2 & 0.13 & 22.1 & 1.70 & $4.00 \mathrm{E}-8$ & 75 & \\
\hline 3 & 0.13 & 20.3 & 1.56 & $5.00 \mathrm{E}-8$ & 60 & \\
\hline 4 & 0.13 & 20.8 & 1.60 & $3.88 \mathrm{E}-8$ & 77 & 4.0 \\
\hline 5 & 0.13 & 19.1 & 1.47 & $4.04 \mathrm{E}-8$ & 74 & 4.8 \\
\hline 6 & 0.13 & 20.8 & 1.60 & $3.98 \mathrm{E}-8$ & 75 & 5.3 \\
\hline 7 & 0.13 & 20.8 & 1.60 & $3.89 \mathrm{E}-8$ & 77 & 5.0 \\
\hline Avg. & & 20.7 & 1.59 & $4.11 \mathrm{E}-8$ & 73 & 4.8 \\
\hline
\end{tabular}

Table 3

TMCTS $+\mathrm{O}_{2}$ Insulators, $30 \mathrm{keV}$

\begin{tabular}{|c|c|c|c|c|c|}
\hline $\begin{array}{c}\text { Pad } \\
\text { No. }\end{array}$ & $\begin{array}{c}t_{O X} \\
(\mathbf{u m})\end{array}$ & $V_{B D}(\mathbf{V})$ & $\begin{array}{c}E_{B D} \\
(\mathbf{M V} / \mathbf{c m})\end{array}$ & $\begin{array}{c}\boldsymbol{I}_{\text {LEAK }} @ \\
\text { 3V (A) }\end{array}$ & $\begin{array}{c}\boldsymbol{R}_{E F F} @ \text { 3V } \\
(\mathbf{M} \Omega)\end{array}$ \\
\hline 1 & 0.13 & 26.2 & 2.10 & $7.94 \mathrm{E}-8$ & 38 \\
\hline 2 & 0.13 & 24.6 & 1.97 & $8.91 \mathrm{E}-8$ & 34 \\
\hline 3 & 0.14 & 27.0 & 1.91 & $1.38 \mathrm{E}-7$ & 22 \\
\hline Avg. & & 25.9 & 1.99 & $1.02 \mathrm{E}-7$ & 29 \\
\hline
\end{tabular}

Whereas the TMCTS-based insulator films have the highest breakdown field of the three types, the OMCTS insulators exhibited the lowest leakage current and thus had the highest effective resistance $\left(R_{E F F}\right)$ of the films characterized in this study. On average, $R_{E F F}$ for the OMCTS-based insulator films is about a factor of 3 greater than that of the $50 \mathrm{keV}$ TMCTS- 
based films, and about 8 times greater than for the TEOS-based films. The TEOS-based films exhibit the lowest $R_{E F F}(25 \mathrm{M} \Omega$ ) as well as the lowest breakdown field. Fig. 6 graphically compares the differences in $E_{B D}$ and $R_{E F F}$ for the FIBinsulators.

There is a large variation in the $R_{E F F}$ values for the OMCTS insulators. The OMCTS data fall into three subgroups, as shown in Fig. 6. The lowest values of $R_{E F F}$ for the OMCTS insulators are similar to those for the $50 \mathrm{keV}$ TMCTS samples. $R_{E F F}$ values for the second and third group were about one-half and one order of magnitude higher, respectively. $E_{B D}$ was higher $(10-20 \%)$ for the OMCTS samples with larger $R_{E F F}$.

Table 4

OMCTS $+\mathrm{O}_{2}$ Insulators, $50 \mathrm{keV}$

\begin{tabular}{|c|c|c|c|c|c|}
\hline $\begin{array}{c}\text { Pad } \\
\text { No. }\end{array}$ & $\begin{array}{c}t_{O X} \\
(\mathbf{u m})\end{array}$ & $V_{B D}(\mathbf{V})$ & $\begin{array}{c}E_{B D} \\
(\mathbf{M V} / \mathbf{c m})\end{array}$ & $\begin{array}{c}I_{L E A K} @ 3 \mathrm{~V} \\
(\mathbf{A})\end{array}$ & $\begin{array}{c}\boldsymbol{R}_{E F F} @ \\
\mathbf{3 V}(\mathbf{M} \Omega)\end{array}$ \\
\hline 1 & 0.13 & 9.6 & 0.74 & $3.16 \mathrm{E}-8$ & 95 \\
\hline 2 & 0.13 & 10.8 & 0.83 & $6.31 \mathrm{E}-9$ & 475 \\
\hline 3 & 0.13 & 10.2 & 0.78 & $5.01 \mathrm{E}-8$ & 60 \\
\hline 4 & 0.13 & 14.4 & 1.11 & $2.50 \mathrm{E}-9$ & 1200 \\
\hline 5 & 0.13 & 15.3 & 1.18 & $5.01 \mathrm{E}-9$ & 600 \\
\hline 6 & 0.13 & 15.6 & 1.20 & $2.24 \mathrm{E}-9$ & 1340 \\
\hline 7 & 0.13 & 13.8 & 1.06 & $2.34 \mathrm{E}-9$ & 1280 \\
\hline Avg. & & 12.8 & 0.99 & $1.43 \mathrm{E}-8$ & 210 \\
\hline
\end{tabular}

Table 5

TEOS + $\mathrm{O}_{2}$ Insulators, $50 \mathrm{keV}$

\begin{tabular}{|c|c|c|c|c|c|}
\hline $\begin{array}{c}\text { Pad } \\
\text { No. }\end{array}$ & $\begin{array}{c}t_{O X} \\
(\mathbf{u m})\end{array}$ & $V_{B D}(\mathbf{V})$ & $\begin{array}{c}E_{B D} \\
(\mathbf{M V} / \mathbf{c m})\end{array}$ & $\begin{array}{c}\boldsymbol{I}_{L E A K} @ 3 \mathrm{3V} \\
(\mathbf{A})\end{array}$ & $\begin{array}{c}\boldsymbol{R}_{E F F} @ \\
\mathbf{3 V}(\mathbf{M} \Omega)\end{array}$ \\
\hline 1 & 0.115 & 9.4 & 0.82 & $1.41 \mathrm{E}-7$ & 21 \\
\hline 2 & 0.115 & 8.6 & 0.75 & $8.32 \mathrm{E}-8$ & 36 \\
\hline 3 & 0.115 & 10 & 0.87 & $9.33 \mathrm{E}-8$ & 32 \\
\hline 5 & 0.138 & 10.4 & 0.75 & $8.32 \mathrm{E}-8$ & 36 \\
\hline 6 & 0.115 & 9.6 & 0.83 & $1.58 \mathrm{E}-7$ & 19 \\
\hline 7 & 0.115 & 8.6 & 0.75 & $2.09 \mathrm{E}-7$ & 14 \\
\hline 8 & 0.115 & 9.2 & 0.80 & $1.00 \mathrm{E}-7$ & 30 \\
\hline 9 & 0.115 & 10 & 0.87 & $7.41 \mathrm{E}-8$ & 41 \\
\hline Avg. & & 9.48 & 0.81 & $1.18 \mathrm{E}-7$ & 25 \\
\hline
\end{tabular}

Chemical Characterization. FIB-deposited insulator pads identical to those used in capacitor fabrication, but without the top contact, were analyzed with microbeam Rutherford backscattering spectrometry (RBS) analysis and micro-Fourier transform infrared (FTIR) spectroscopy to determine their chemical composition and structure.
Microbeam RBS was performed with an NEC model 5SDH RBS Spectrometer. The system uses singly-charged He ions accelerated to $1.5 \mathrm{MeV}$ and has a current density of $10 \mathrm{nA}$ over a nominal beam diameter of $20 \mu \mathrm{m}$ [9]. Data were collected at a $160^{\circ}$ scattering angle, and SCATT software was used for data analysis. The RBS data are summarized in Table 6. The RBS results are expressed in terms of atomic \%.

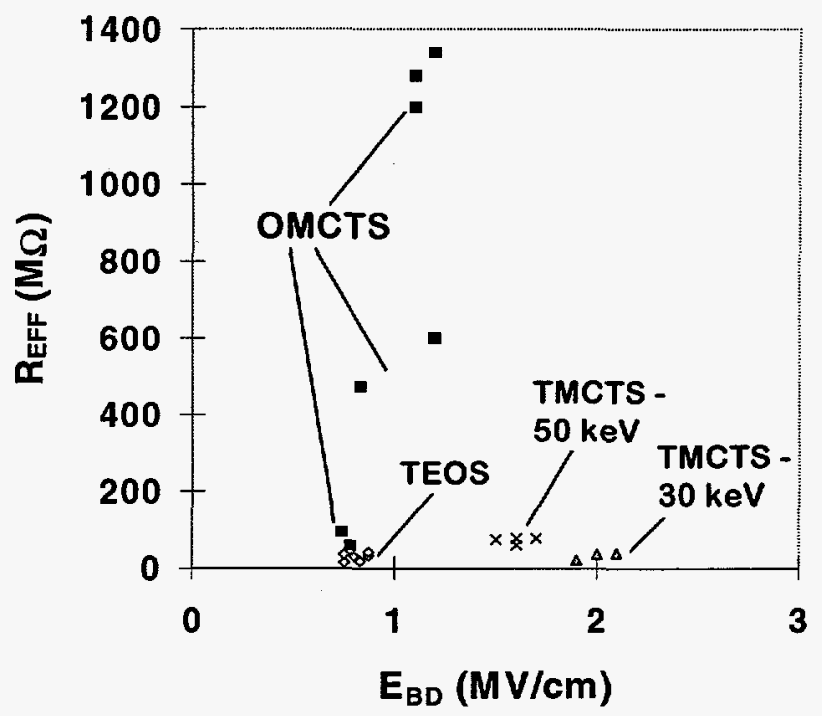

Fig. 6. $E_{B D}$ and $R_{E F F}$ for the FIB-insulators produced in this study.

The RBS results indicate that while the Si:O ratio in the films is basically stoichiometric, a significant amount of $\mathrm{Ga}$ is incorporated into the films, similar to the previously reported results for insulators deposited from siloxane and oxygen [6]. The surface of the insulator deposit is depleted of Ga relative to the bulk of the film as has been observed previously [6]. The thickness of the depleted region was estimated to be $300 \AA$.

The RBS spectra also indicated that the bottom $600-750 \AA$ of the nominally $1300 \AA$ thick FIB-insulator films was a mixed region, containing $\mathrm{Al}$ from the substrate as well as $\mathrm{Si}, \mathrm{O}$, and Ga. This mixed region had not been noted previously, most likely because a polycrystalline Si substrate was used in the earlier experiments [6], rather than a chemically distinct material such as the Al substrate used in this work. The composition of the mixed region varies with depth, containing close to $100 \% \mathrm{Al}$ at the deepest part of the region and very little $\mathrm{Al}$ at the top of the layer. The $\mathrm{Ga}$ content of the mixed region ranges from $5-8 \%$, with $\mathrm{Si}$ and $\mathrm{O}$ in stoichiometric proportion making up the balance of the film. Table 6 shows that the mixed region is less extensive for the TMCTS deposits performed at lower energy $(30 \mathrm{keV})$. A mixed region of approximately $600 \AA$ was observed for the $30 \mathrm{keV}$ TMCTS deposition, as compared with $700 \AA$ for the $50 \mathrm{keV}$ TMCTS deposit. These observations are consistent with deeper $\mathrm{Ga}$ penetration, and thus greater mixing, when a higher energy ion beam is used. 
Table 6

RBS and FTIR Results

\begin{tabular}{|c|c|c|c|c|c|c|c|c|c|c|}
\hline \multirow[t]{2}{*}{ Film } & \multicolumn{4}{|c|}{ Surface Region } & \multicolumn{4}{|c|}{ Main Film } & \multirow{2}{*}{$\begin{array}{l}\text { Mixed } \\
\text { Region }\end{array}$} & \multirow{2}{*}{$\begin{array}{c}\text { Si-O-x Stretch } \\
\left(\mathrm{cm}^{-1}\right)\end{array}$} \\
\hline & $\mathbf{t}(\AA)^{*}$ & $\% \mathrm{Si}$ & $\% 0$ & $\% \mathrm{Ga}$ & $\mathbf{t}(\AA)^{*}$ & $\% \mathrm{Si}$ & $\% 0$ & $\% \mathrm{Ga}$ & & \\
\hline $\begin{array}{l}\text { TMCTS** } \\
(30 \mathrm{keV})\end{array}$ & 300 & 32 & 64 & 4 & 1000 & 29 & 59 & 12 & 600 & 1222 \\
\hline $\begin{array}{c}\text { TMCTS } \\
(50 \mathrm{keV})\end{array}$ & 300 & 32 & 64 & 4 & 600 & 28 & 59 & 13 & 700 & $1210-1225$ \\
\hline OMCTS & 350 & 32 & 64 & 4 & 600 & 27 & 56 & 17 & 700 & $1190-1200$ \\
\hline TEOS & 400 & 32 & 64 & 4 & 700 & 24 & 48 & 28 & 750 & $1190-1200$ \\
\hline
\end{tabular}

*Note: The thickness measurements are relative, not absolute. A rigorous calculation of the absolute thickness of the surface, main film, and mixed interface regions would require knowledge of the density in these regions, which has been estimated for the calculations but is not known.

** This FIB-insulator pad was approximately $2000 \AA$ thick.

FTIR spectroscopy $[10,11]$ was performed with a Nicolet 740 spectrophotometer equipped with a Spectratech IR-PLAN infrared microscope accessory. Infrared reflectance spectra were collected from 600 to 4000 wave numbers $\left(\mathrm{cm}^{-1}\right)$. Reflectance mode was used due to the non infrared-transparent Al film on the substrate used for FIB oxide depositions.

The absorption peak associated with the stretching mode in the Si-O bonds, which normally occurs at $1100 \mathrm{~cm}^{-1}$ was shifted to $1190-1222 \mathrm{~cm}^{-1}$ for the FIB-insulators (Table 6). This shift of the Si-O stretch to higher wavenumbers is contrary to the earlier finding of Abramo et al [6], which showed a shift to lower wavenumbers in transmission mode. The MFTIR spectra showed no evidence of $\mathrm{C}-\mathrm{H}$ or $-\mathrm{SiH}$ stretching. These data indicate that the organic impurities and silanic hydrogen from precursors or deposition tool contaminants had not been incorporated into any of the films at significant concentrations.

\section{Discussion}

The large difference in deposition yield for FIB-insulators produced from TMCTS, OMCTS, and TEOS may be explained at least qualitatively in terms of the differences in molecular structure. The siloxane compounds (TMCTS and OMCTS) are relatively reactive ring structures, with each $\mathrm{Si}$ atom bonded to one or more methyl $\left(-\mathrm{CH}_{3}\right)$ groups as well as two oxygen atoms. During insulator deposition in the FIB, the siloxane molecule reacts with oxygen and dissociates, and $\mathrm{SiO}_{2}$ is formed. Our experimental results indicate that the reaction rate is 1.5 times faster for TMCTS, which is the simpler siloxane molecule containing only one methyl group per Si atom, compared to OMCTS which contains two methyl groups for each Si. Compared with the siloxanes, TEOS is a more rigid, stable molecule with $8 \mathrm{C}$ atoms per $\mathrm{Si}$, and not surprisingly has a much lower deposition yield (5.5 - 8.5 times slower) than the siloxanes.

As shown in Table 6, the ratio of silicon to oxygen in all of the FIB-insulators produced in this study was stoichiometric. Further, there was no evidence of significant incorporation of $\mathrm{C}$ into the insulator films. These results are very different from the previous finding that TEOS-based FIB-insulator films formed without oxygen codeposition contain a significant amount of $\mathrm{C}$ and less $\mathrm{O}$ than is prescribed by stoichiometry $[3,4]$. This underscores the importance of the role of oxygen in producing high quality FIB-insulators.

The RBS data in Table 6 indicate that the fraction of Ga incorporated into the various FIB-insulators scales inversely with the relative deposition yield (Table 1). TMCTS has the highest yield and the lowest percentage $(12-13 \%)$ of $\mathrm{Ga}$, followed by OMCTS $(17 \%)$ and TEOS (28\%). This indicates that the longer it takes (in other words, the greater the ion dose required) to deposit a given thickness of insulator material in the FIB system, the larger will be the fraction of incorporated Ga. To a first approximation, it would be expected that the insulator with the lowest $\mathrm{Ga}$ content would have the best electrical properties. Our findings show that while the insulator with lowest Ga content (TMCTS) has the greatest resistance to electrical breakdown, the OMCTS films with somewhat higher Ga content actually had the lowest leakage current and highest $R_{E F F}$. Understanding the reason for this behavior would require understanding the defects and conduction mechanism in these materials, which will require further study.

Figure 7 compares a typical FIB-insulator $I-V$ curve with the expected $I-V$ curve if Fowler-Nordheim tunneling were the leakage mechanism. The Fowler-Nordheim curve is computed from the low voltage portion of the FIB-insulator $I-V$ curve. Fig. 7 clearly shows that the leakage is higher for the FIBinsulator than for Fowler-Nordheim tunneling case (i.e., classic gate oxide) as breakdown is approached. Because of the high 
content of conductive metal impurities (Ga) in the FIBinsulators, it is not surprising that the conduction mechanism at higher fields has a different functional dependence on the applied voltage and that the resulting leakage current is higher than the Fowler-Nordheim mechanism would predict.

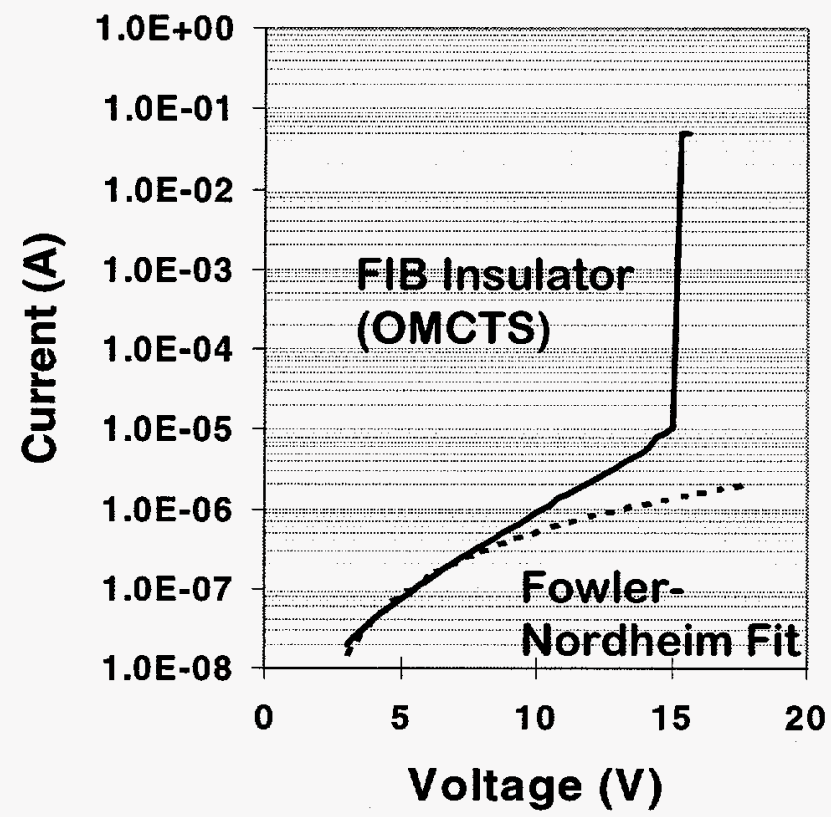

Fig. 7: Comparison of FIB-insulator $I-V$ behavior with FowlerNordheim tunneling fit to the data.

Figure 8 compares the breakdown data, plotted in terms of electric field $(E)$ vs. current density $(J)$ for capacitors produced in the FIB with those fabricated by other methods. In each case, the voltage was stepped linearly and the current was measured after each step. The gate oxide (GOX) data was from a thermally grown, $0.001 \mathrm{~cm}^{2}$ area, $110 \AA$ gate oxide capacitor. The data marked PECVD is from $0.096 \mathrm{~cm}^{2}$ capacitors made with plasma enhanced chemical vapor deposition at $300^{\circ} \mathrm{C}$ using a TEOS precursor. This is typical of oxide materials used as interlevel dielectrics. The FIB-insulator has the highest leakage current of the three, but it can survive a higher current density before breakdown than the PECVD oxide. Breakdown is indicated in Fig. 8 at the point that the or $J-E$ curves increase in slope abruptly.

The measured capacitance values for the TMCTS insulators are roughly four times greater than would be expected assuming an effective dielectric thickness of $1000 \AA$, that the dielectric constant of the FIB-insulators is close to that of $\mathrm{SiO}_{2}$ (3.9), and that the area of the capacitors is the size of the W top electrode, $60 \mu \mathrm{m} \times 60 \mu \mathrm{m}$. The capacitance value is directly proportional to the insulator's dielectric constant and the area of the capacitor, and is inversely proportional to the insulator thickness. The RBS data indicate that the effective dielectric thickness (main film plus surface depletion layer) is close to $1000 \AA$. This implies that either the effective area of the capacitor is larger than that of the top electrode or that the dielectric constant of the FIB-deposited insulator is higher than that of $\mathrm{SiO}_{2}$, or that a combination of the two effects occurs. As described in the Experimental Approach section, a conductive overspray typically forms a halo around FIBdeposited conductors, which would increase the effective cross sectional area of the capacitors fabricated in the FIB. Overspray of approximately $30 \mu \mathrm{m}$ around the conductor would not be unusual, and would increase theeffective area of the capacitors by a factor of 4 (i.e., to $120 \mu \mathrm{m} \mathrm{x} 120 \mu \mathrm{m}$ ). It would be necessary to know the actual capacitor area to be able to calculate the dielectric constant for the FIB-deposited insulator materials. This could be achieved by performing a clean-up mill after depositing the top electrode, or by using a different process, such as lithographic masking and sputter deposition, to produce the top contacts.

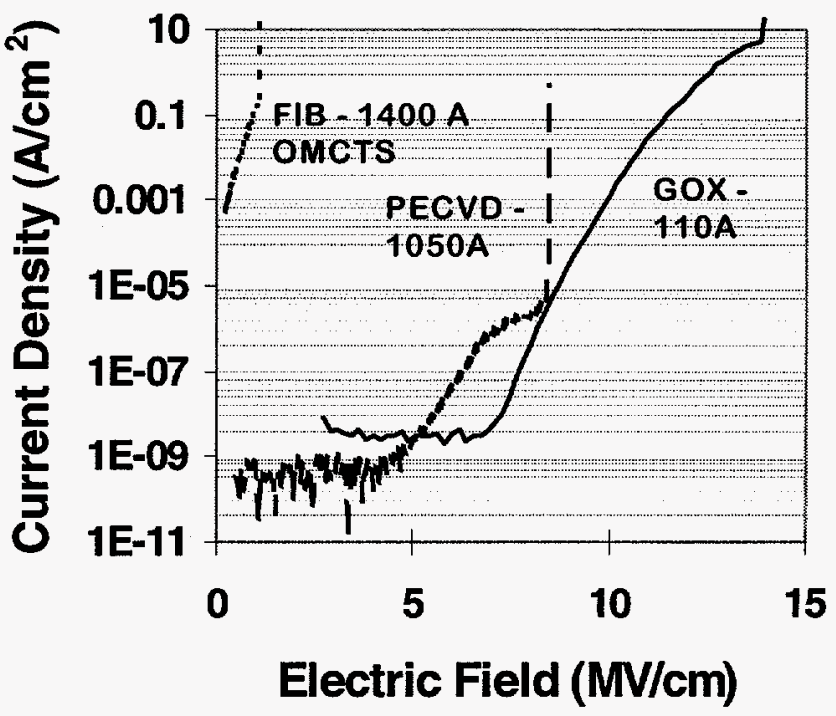

Fig. 8. Comparison $J-E$ behavior of the FIB-insulator material with PECVD and gate oxides.

The $R_{E F F}$ of the FIB-insulators produced in this study are 3 5 orders of magnitude smaller than those reported previously for silxoane-based FIB-insulators [6]. However, when the differences in geometry between the two types of test structures are taken into account, the effective resistivities calculated from the resistance data are found to be quite similar $\left(\sim 10^{9} \mu \Omega-\mathrm{cm}\right)$.

The RBS results shown in Table 6 indicated significant mixing of the FIB-insulator with the $\mathrm{Al}$ substrate, reducing the effective thickness of the insulator layer from the nominal 1300 $\AA \AA$ to approximately $1000 \AA$ or less. This means that the actual $E_{B D}$ is somewhat $(\sim 15-25 \%)$ higher than is shown in Tables 2 - 5. Further, the RBS data in Table 6 show that there is approximately $15 \%$ less mixing at the interface for the $30 \mathrm{keV}$ TMCTS insulators than for those deposited at $50 \mathrm{keV}$. This implies that the effective insulator thickness is actually larger for the $30 \mathrm{keV}$ TMCTS samples, which is consistent with the experimental observation that $E_{B D}$ is lower for the $50 \mathrm{keV}$ TMCTS insulators compared with those fabricated at $30 \mathrm{keV}$ (see Tables 2 and 3). Finally, the occurrence of mixing at the 
interface between FIB-deposited insulators and metals has significant implications for the performance of IC modifications, particularly when depositing the FIB-insulator on thin metallic layers or when depositing very thin insulator layers on metals. On the other hand, extensive mixing at the interface probably indicates good adherence of the FIBinsulator films.

\section{Conclusions}

A metal-insulator-metal capacitor structure was used successfully to characterize the electrical behavior of FIBdeposited insulator materials. Of the three precursors codeposited with oxygen, it was found that TMCTS-based films had the highest breakdown field, OMCTS-based films had the lowest leakage and highest effective resistance, and the TEOS-based insulators had the worst overall electrical performance. RBS analysis indicated that all of the films contained incorporated $\mathrm{Ga}$, and that the TEOS-based films contained 1.5 - 2 times as much $\mathrm{Ga}$ ( 28 atomic \%) as the siloxane-based films. RBS analysis also showed that an appreciable amount of mixing occurs at the interface between FIB-deposited conductors and metals, which reduces the effective insulator thickness and can have significant implications for performing circuit modifications. The RBS data indicated that $\mathrm{Si}$ and $\mathrm{O}$ are present in a stoichiometric ratio in the FIB-insulator films. Both RBS and FTIR indicated that the films did not contain a significant number of impurities other than $\mathrm{Ga}$ due to implantation and $\mathrm{Al}$ due to mixing.

The $I-V$ characteristics of the FIB-insulators differ considerably from what is expected based on the FowlerNordheim conduction mechanism which typically applies for gate oxide materials. The increased leakage current at higher voltage is not inconsistent with the high Ga content of these materials. However, the details of the conduction mechanism are not understood at this time. Capacitance measurements were successfully performed and suggest that the dielectric constant of the TMCTS-based insulators is not significantly different from that of $\mathrm{SiO}_{2}$. Clearly, more work will be required to fully understand and possibly improve the electrical behavior of the FIB-deposited insulator materials.

\section{Acknowledgments}

The authors thank Jim Rife, Ric Bradley, Lila Zurzolo, Scot Swanson, Loren Hahn, Alex Pimentel, and Ken Peterson for their contributions to this study. This work was performed at Sandia National Laboratories, a multiprogram laboratory operated by Sandia Corporation, a Lockheed Martin company, for the U. S. Department of Energy under contract number DEAC04-94AL85000.

\section{References}

1.) H. Komano, H. Nakamura, and T. Takigawa, "A Rewiring Technique for Integrated Circuit Operation Analysis Using a Silicon Oxide Film Deposited by a Focused Ion Beam," J. Vac. Sci. Technol. B 9, 2653 (1991).

2.) M. T. Abramo and L. L. Hahn, "The Application of Advanced Techniques for Complex Focused Ion Beam Device Modification", Microelectron. Reliab. 36 (11/12), 1775 (1996).

3.) J. R. Baker, "Focused Ion Beam Insulator Deposition," Proc. 21st Internat. Symp. for Testing and Failure Analysis, 6 10 Nov. 1995, Santa Clara, CA, pp. 43 - 47.

4.) J. R. Baker, private communication.

5.) M. Abramo, L. Hahn, L. Moskowicz, A. Doyle, and D. Stewart, "Focused Ion Beam Induced Insulator Deposition: An Advanced Technique for Device Modification," Proc. $6^{\text {th }}$ European Symposium on Reliability of Electron Devices, Failure Physics, and Analysis, 1995, pp. 313 - 317.

6.) M. Abramo, E. Adams, M. Gibson, L. Hahn, and A. Doyle, "Focused Ion Beam Induced Insulator Deposition at Decreased Beam Current Density," Proc. $35^{\text {th }}$ Internat. Rel. Phys. Symp., 8 - 10 April 1997, Denver, CO, pp. 66 - 71.

7.) M. Tabasky, E. S. Bulat, B. Tweed, and C. Herrick, "Investigation of Thick, Low-Temperature Plasma Deposited Silica Films for Waveguide Fabrication," J. Vac. Sci. Technol. A 12 (4), 1244 (1984).

8.) M. Ogasawara, M. Kariya, H. Nakamura, H. Komano, S. Inoue, K. Sugihara, N. Hayasaka, K. Horioka, T. Takigawa, Y Yamazaki, M. Miyoshi, T. Watanabe, and K. Ohumura, "Beam Induced Deposition of an Ultraviolet Transparent Silicon Dioxide Film by Focused Gallium Ion Beam," Appl. Phys. Lett. 68 (6), 732 (1996).

9.) G. M. Klody, J. B. Schroeder, J. A. Ferry, T. J. Pollock, and E. D. Adams, "A $5 \mathrm{MeV}$ Microprobe for Materials Analysis in the Semiconductor Industry," Nuclear Instruments and Methods in Research B 56 - 57, 704 (1991).

10.) P. R. Griffiths, Chemical Infrared Fourier Transform Spectroscopy, John Wiley and Sons, New York, NY, 1975.

11.) R. A. Nyquist and R. O. Kagel, Infrared Spectra of Inorganic Compounds, Academic Press Inc., New York, NY, 1971.

\section{DISCLAIMER}

This report was prepared as an account of work sponsored by an agency of the United States Government. Neither the United States Government nor any agency thereof, nor any of their employees, makes any warranty, express or implied, or assumes any legal liability or responsibility for the accuracy, completeness, or usefulness of any information, apparatus, product, or process disclosed, or represents that its use would not infringe privately owned rights. Reference herein to any specific commercial product, process, or service by trade name, trademark, manufacturer, or otherwise does not necessarily constitute or imply its endorsement, recommendation, or favoring by the United States Government or any agency thereof. The views and opinions of authors expressed herein do not necessarily state or reflect those of the United States Government or any agency thereof. 